\title{
Near infrared spectrometry for faecal fat measurement: comparison with conventional gravimetric and titrimetric methods
}

\author{
L BENINI, S CALIARI, G C GUIDI, B VAONA, G TALAMINI, I VANTINI \\ AND L A SCURO
}

From the Istituto di Clinica Medica, University of Verona, Divisione di Gastroenterologia and Laboratorio di Chimica Clinica at Valeggio sM, University of Verona, Verona, Italy

SUMmaRy This investigation was aimed at comparing a new method for measuring faecal fat excretion, carried out with a semi-automated instrument by using near infrared analysis (NIRA), with the traditional titrimetric (Van de Kamer) and gravimetric (Sobel) methods. Near infrared analysis faecal fat was assayed on the three day stool collection from 118 patients (68 chronic pancreatitis, 19 organic diseases of the gastrointestinal tract, 19 alcoholic liver disease, 12 functional gastrointestinal disorders). A strict linear correlation was found between NIRA and both the titrimetric $(r=0.928, p<0.0001)$ and the gravimetric $(r=0.971, p<0.0001)$ methods. On homogenised faeces, a mean coefficient of variation of $2 \cdot 1$ (SD 1.71)\% was found. Before homogenisation (where a mean coefficient of variation of $7 \%$ was found) accurate results were obtained when the mean of five measurements was considered. In conclusion, the assay of faecal fat excretion by the near infrared reflessometry appears a simple, rapid and reliable method for measuring steatorrhoea.

Fat malabsorption represents a sign of several pancreatic, intestinal and biliary diseases. Its quantification is important in the follow up and in the therapy monitoring of such patients, and many methods (gravimetric, ${ }^{1}$ titrimetric, ${ }^{23}$ colorimetric, ${ }^{4}$ spectrophotometric, ${ }^{5}$ with nuclear magnetic resonance $^{h}$ ) have been suggested. They are, however, not widely used in clinical practice because they require prolonged manipulation of stools and are rather complex and time consuming. Fat, starch, and nitrogen have recently been measured in stools by near infrared reflectance analysis, ${ }^{78}$ a method increasingly used in clinical chemistry for direct measurement of composite materials. Results are obtained in less than one minute from small quantities $(2-3 \mathrm{~g})$ of unprocessed faeces. The aim of this study was to evaluate the efficiency of this method, and to compare it with the most widely used titrimetric and gravimetric methods.

Address for correspondence: Dr Luigi Benini. Dept Gastroenterology. Ospedale. 37067 Valeggio SM. (Verona). Italy.

Accepted for publication 21 February 1989.
Methods

\section{PATIENTS}

We prospectively studied 118 patients $(99 \mathrm{men}, 19$ women, age range 19-72 years) admitted to our ward because of a clinical picture suggesting malabsorption (increased bowel frequency, weight loss) or because of diseases known to cause malabsorption. Their final diagnoses are shown in the Table. The diagnosis of intestinal diseases was made up by Crohn's disease (four), untreated coeliac disease (two), and protein losing enteropathy (one). In the patient with protein losing enteropathy severe pancreatic insufficiency was found, but considered secondary to protein loss.

Table Final diagnoses of the studied patients

$\begin{array}{lr}\text { Functional disorders } & 12 \\ \text { Previous gastroresection } & 6 \\ \text { Intestinal diseases } & 7 \\ \text { Alcoholic liver disease } & 19 \\ \text { Past acute pancreatitis } & 6 \\ \text { Chronic pancreatitis } & 68\end{array}$


Patients with past acute pancreatitis were readmitted for re-evaluation of the pancreatic function and morphology one year after a severe acute attack; endoscopic retrograde pancreatography and a Secretin-Cacrulein test were within normal limits. Most patients with chronic pancreatitis were readmitted as part of a longterm study on the natural history of the disease. Pancreatic extracts and all other drugs, except insulin, were stopped three days before the study, and no barium study was carried out. Fat balance was carried out in the patients on a $100 \mathrm{~g}$ fat diet for five days. In 18 patients faecal excretion was also measured for three days on a standard hospital diet (60)-70 $\mathrm{g}$ fat for day). Stools from the last three days were collected, weighed, homogenised and two samples of $20-30 \mathrm{~g}$ were stored at $-20^{\circ} \mathrm{C}$ for fat assays, always performed within three weeks. Initially the study protocol implied measurement of faecal fat by near infrared reflectance analysis and by the titrimetric method only. In the last 40 patients the gravimetric method was added, in an attempt to explain any conflicting data.

FAECAL FAT MEASUREMENT

\section{Titrimetric method}

A slight modification of the usual Van de Kamer method was used to improve its accuracy, by continuous recording of the titration curve (RTS 822 Automatic Titration System, Radiometer, Copenhagen). This avoided variations in results found with $\mathrm{pH}$ indicators, caused by transient changes in colour because of the low dissociation coefficient of fatty acids. We chose $\mathrm{pH} 8.3$ as the final point of the reaction, because at this value we consistently found the steepest change of the slope after the plateau due to the buffering action of fatty acids.

\section{Gravimetric method}

The Sobel method was followed using three extractions with petrol ether of an acidified faecal cmulsion: the ether is then evaporated, the residue dried overnight and finally weighed.

\section{Near infrared analysis}

This assay was carried out by using a 450 InfraAlyzer (Technicon Instrument Corporation, Rome, Italy). The method is based on the analysis of the radiation in the infrared spectrum close to the visible spectrum reflected by the surface of the material under study. Specific peaks for the component to be investigated were identified and their height was related to its concentration by computerised multilinear regression analysis, as already described." Data of total fat concentration are derived using an equation taking into account the reflectance of the analyte at various wavelengths, the characteristics of the absorbance filters used for measurement and a correction factor for bias. In practice, a small quantity of facces is put in a small plastic bowl, and covered with a glass slide to level the surface. The bowl is then inserted into the instrument for an automatic reading of the results.

To assess the reproducibility of the measurement, in 12 patients we measured fat concentration in three different samples obtained after the homogenisation. Moreover, in four patients we measured fat concentration in 20 samples obtained from different parts of the faecal collection before the homogenisation.

STATISTICAI. ANALYSIS

Pearson's correlation coefficient $r$ was used. Data distribution were log-normal (as confirmed by a nonsignificant Kolmogorov-Smirnov test only after logarithmic transformation of the data), and a better correlation between observed and expected residuals was found after logarithmic transformation of the data. The correlation coefficients were therefore first calculated after logarithmic transformation. A linear correlation curve was also found, however, between natural data. For the large number of patients studied, negligible differences were found between correlation cocfficients and significance levels calculated from the $\log$ transformed and the original untransformed data. The latter are therefore considered for clarity.

\section{Results}

In our patients by the NIRA method a faecal fat output ranging from 1 to $95 \mathrm{~g} / \mathrm{d}$ was found (median $10 \cdot 5)$. These values were very stable, and almost no difference was found between stools freshly produced and after two day storage at room temperature or four weeks at $-20{ }^{\circ} \mathrm{C}$. A mean coefficient of variation of $2 \cdot 1 \%$ (SD 1.71) was found on homogenised faces. When readings were performed on multiple samples obtained from faeces not yet homogenised, a mean coefficient of variation of $7 \%$ was found: the average rate for five determinations of inhomogenised faeces was always within $10 \%$ of values obtained for homogenised samples. When the faecal fat output was measured before and during the $100 \mathrm{~g}$ fat/day diet, no difference was found in the nine patients with a faecal fat output less than $8 \mathrm{~g} / \mathrm{day}$. On the contrary, faecal fat excretion was lower on the hospital diet than on the fat rich diet in six of nine patients with a steatorrhoea (without diet) $>8$ g/day. Overall, the mean faecal fat excretion was $15 \cdot 8 \mathrm{~g}$ /day not on diet $v \cdot 23.5$ on diet $(\mathrm{p}<0 \cdot(070$, Wilcoxon's test $)$. Figures 1 and 2 show the relationship between faecal fat output calculated by near infrared analysis and the output calculated either using the titrimetric or the gravimetric method. A similar correlation was found 


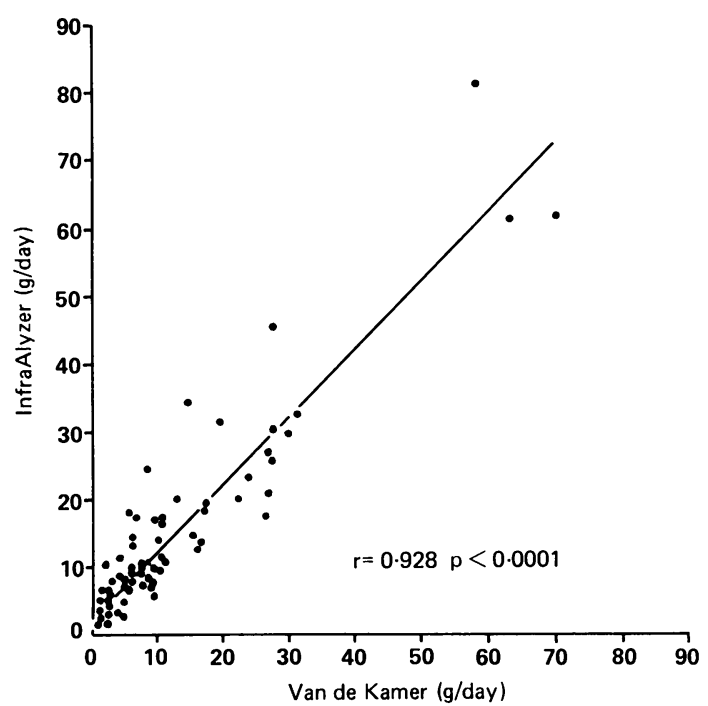

Fig. 1 Correlation between faecal fat output measured with the reflessometric method (InfraAlyzer) and with the titrimetric method (Van de Kamer).

between the well established titrimetric and gravimetric methods $(r=0.962)$. Similar figures were obtained after logarithmic transformation of the data (NIRA $v$ titrimetry $\mathrm{r}=0.92$; NIRA $v$ gravimetry $r=0.95$; titrimetry $v$ gravimetry $r=0.938$ ). The differences in each sample between either the gravimetric or the near infrared analysis methods and the titrimetric one were again significantly correlated $(r=0 \cdot 63, p<0 \cdot 0001)$ to suggest that a slightly different substrate is read by the titrimetric method.

\section{Discussion}

Direct methods for measuring faecal fat losses are complex and poorly accepted by laboratory staff. Even the most recent method (nuclear magnetic resonance) requires homogenisation and freeze drying of stools." This explains why so many but sometimes inaccurate indirect tests - for example, oxalate urinary excretion - have been described. Some tests require radioactive isotopes administration"-11; this makes repeated analyses impossible and only semiquantitative data are obtained. For example, in the ${ }^{14} \mathrm{C}$-triolein breath test a negative exponential correlation curve is found between faecal fat output and radioactive excretion. This means that an abnormal test can be obtained in patients with either borderline or severe steatorrhoea. Moreover, these tests give an indication of the digestion and absorption of the small test meal only

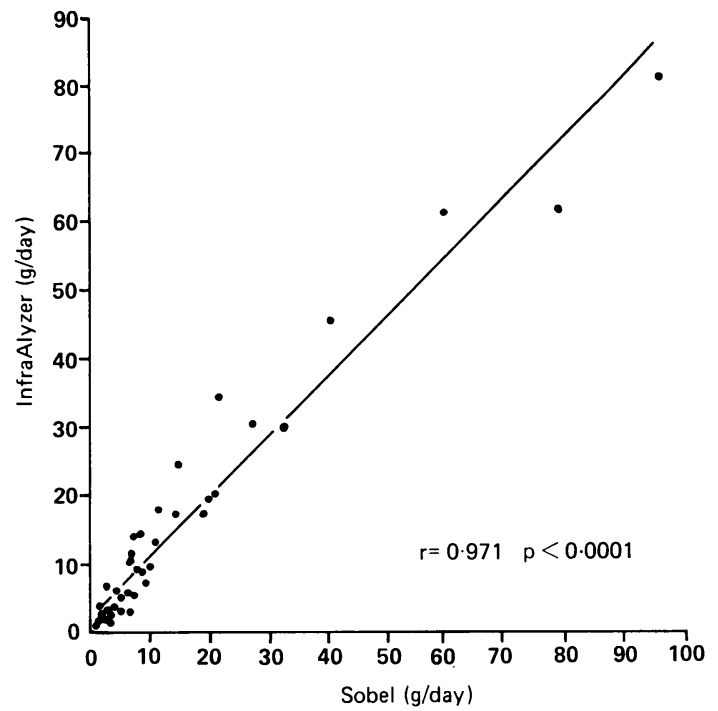

Fig. 2 Correlation between faecal fat output measured with the reflessometric method (InfraAlyzer) and with the gravimetric method (Sobel).

and not of a normal diet and therefore cannot be used in monitoring treatment."

Near infrared analysis could represent a solution as it is simple, quick, and implies the handling of small quantities of stools. Repeated analysis on different parts of the same collection, performed in a few minutes, can avoid homogenisation, probably the most unpleasant part of the assay. The mean of five readings reduces to less than $10 \%$ the difference from the value obtained after homogenisation. This means that faecal fat can be quantified very quickly after each movement, without storing bulky collections. A normal result seems to rule out malabsorption even without the fat rich diet. Moreover, as no complicated procedure is involved, nurses can perform the test, and this is already routine in our department for patients with malabsorption. A strict linear correlation was found with the most widely used chemical methods, and particularly with the gravimetric one. This could easily be anticipated considering that the titrimetric method measures total fatty acids from dietary sources or from desquamated cells, present as glycerides or as free fatty acids. The gravimetric and the NIRA methods measure, in addition, other nonhydrolysable fats.

The high price of the sophisticated instrument used in this study (approximately $£ 18000$ in Italy) will probably be reduced by simpler versions which are at present being developed. Other possible uses for this instrument - for example, to assay nitrogen balance 
in patients on enteral nutrition, require further studies.

We wish to thank Miss M T Brentegani and Miss W Bertaiola for their excellent technical assistance, and all the nurse staff of the Valeggio sM Hospital for their helpful cooperation. We also wish to thank Mrs Carol Thomas for reviewing the English. Part of these data have been presented at the Autumn Mecting of the British Society of Gastroenterology, Sheffield, 14-16 September 1988 (abstracted in Gut 1988; 29: A 1459) and at the 3rd Meeting of the International Society of Pancreatology, Verona, 1-3 September 1988 (abstracted in Int J Pancreatol 1988: 3 (suppl 2): S233).

\section{References}

1 Henry RJ. Clinical chemistry: principles and technics. New York: Harper and Row, 1964: 881.

2 Van de Kamer JH. Huinink HB. Wevers HA. Rapid method for the determination of fat in feces. J Biol Chem 1949: 177: 347-55.

3 Van de Kamer JH. Total fatty acids in stool. In: Seligson D. ed. Standard methods of clinical chemistry. New York: Academic Press. 1958: 2: 34.
4 Tomaszewski L. Rapid and accurate method for determination of total lipids in feces. Clin Chim Acta 1975: 61: 113-20.

5 Fales FW. Evaluation of a specrophotometric method for determination of total fecal lipids. Clin Chem 1971: 17: 1103-8.

6 Schneider MU. Demling L. Jones SA. et al. NMR Spectrometry. A new method for total stool fat quantification in chronic pancreatitis. Dig Dis Sci 1987: 32: 494-9.

7 Maschio C. Tomei E. Leonardis B. Cardinale E. Seri S. Valutazione della digestione e dell assorbimento dei nutrienti nel sano ed in alcune condizioni di malassorbimento, mediante lesame delle feci con un sistema automatizzato. G Cl Med 1984: 65: 133-47.

8 Peuchant E. Salles C. Jensen R. Value of a spectroscopic 'Fecalogram' in determining the etiology of steatorrhea. Clin Chem 1988: 34: 5-8.

9 Newcomer AD. Hofmann AF. DiMagno EP. Carlson GL. Triolein breath test: a sensitive and specific test for fat malabsorption. Gastroenterology 1979; 76: 6-13.

10) Thorsgaard Pedersen N. Nybol Andersen B. Margversen J. Estimation of "C-triolein assimilation or measurement of serum radioactivity? Scand J Gastroenterol 1982: 17: 309-16.

11 Benini L. Scuro LA. Menini E. et al. Is the C-triolein breath test useful in the assessment of malabsorption in clinical practice? Digestion 1984: 29: 91-7. 